\title{
Política Nacional de Humanização (PNH): um Estudo a Partir de Estudantes de Medicina.
}

\author{
Storer, Ivania da Conceição Alves; Batista, Sylvia H. S da Silva; Storer, Fábio Luiz; Silva, \\ Adriana Dias \\ Universidade Federal de São Paulo — ivania.storer@yahoo.com.br
}

Introdução: o SUS, como parte integrante de política favorável à construção de justiça social e do bem-estar entre brasileiros, tem sido, de certo modo, consenso entre os estudiosos do tema. Entretanto, não se pode responsabilizar apenas a questão saúde, considerando que seu conceito é muito mais abrangente do que a simples ausência de doença, posto que a economia, educação e cultura de um povo influenciam diretamente sua concepção do processo saúde-doença. Neste contexto, a PNH emerge como uma das políticas de saúde de abrangência nacional que visa à reorganização dos processos de trabalho em saúde e para a saúde, com propostas de intervenção nas relações sociais, envolvendo trabalhadores, gestores e usuários do SUS. As mudanças desejadas nos serviços de saúde somente ocorrerão com políticas públicas eficazes e mudanças nas disciplinas que integram os currículos dos cursos de saúde. Essas transformações refletem diretamente nas relações pessoais dos médicos e também em suas relações com o paciente. Objetivo Geral: analisar as concepções dos discentes de medicina da Universidade Federal de um estado da região norte do país sobre a Política Nacional de Humanização (PNH). Objetivos específicos: Descrever as vivências em humanização dos estudantes no internato do curso de medicina; Identificar as dificuldades percebidas pelos estudantes para que a humanização seja efetivamente trabalhada no curso de medicina da universidade; Discutir as concepções dos estudantes no âmbito da formação médica mais humanizada. Método: Trata-se de um estudo qualitativo, do tipo descritivo-exploratório, realizado com 25 graduandos do $12^{\circ}$ período do curso médico, produzindo-se dados a partir de grupo focal e os analisando na perspectiva do conteúdo, tipo análise temática. com base nos núcleos direcionadores, foram construídas categorias. Resultados: a fragmentação no currículo, sinalizada pelos discentes quanto ao ensino teórico e vivência da humanização nas atividades práticas das disciplinas e do internato, especialmente sobre a Política Nacional de Humanização, foi considerada um dos desafios para melhoria da educação médica. Conclusões: Emergiu desta discussão a necessidade de integrar disciplinas de forma a possibilitar um conteúdo programático de natureza interdisciplinar. Assim, buscando ampliar o debate, a criação de um Núcleo de Estudos de Humanidades em Saúde configura-se como o produto deste trabalho. Desenha-se um núcleo, onde sejam realizadas rodas de conversas, nas quais alunos e professores possam se expressar a respeito das aprendizagens sobre Humanização e Política Nacional de Humanização. Acredita-se que a divulgação dos resultados deste trabalho e a corroboração dos achados de outros estudos são necessárias para aprofundar a discussão acerca do ensino médico, o que pode contribuir para uma formação mais humana, contemplada também nos currículos acadêmicos.

Palavras-chave: Ensino Médico. Humanização em saúde. Estudante. Política Nacional de Humanização.

Storer, Ivania da Conceição Alves; Batista, Sylvia H. S da Silva; Storer, Fábio Luiz; Silva, Adriana Dias. Política Nacional de Humanização (Pnh): um Estudo a Partir de Estudantes de Medicina.. In: Anais do Congresso Internacional de Humanidades \& Humanização em Saúde [= Blucher Medical Proceedings, num.2, vol.1]. São Paulo: Editora Blucher, 2014. ISSN 2357-7282

DOI 10.5151/medpro-cihhs-10421 